\title{
BONE MORPHOGENETIC PROTEIN-2 AND COLLAGEN TYPE 1 FROM DIFFERENT SOURCES OF DEMINERALIZED DENTINE MATRIX: RELEASE KINETIC AND CHEMOTAXIS POTENTIAL FOR OSTEOPROGENITOR CELLS
}

\author{
JIBO BA0 ${ }^{1,2 \#}$, JUN H. E. ${ }^{3 \#}$, ZILIANG L. I. ${ }^{3,4}$, RONGQIANG YANG ${ }^{5}$, JINYANG ZOU ${ }^{4}$, YIXIN DING ${ }^{4}$, TAO NIU ${ }^{4}$, \\ ZHIGANG XIE ${ }^{2,4 *}$, DUTMANEE SERIWATANACHAI ${ }^{1 *}$
}

\begin{abstract}
${ }^{1}$ Department of Oral Biology, Faculty of Dentistry, Mahidol University, Rajthevi, Bangkok, Thailand. ${ }^{2}$ Department of Implantology and Prosthodontics, The Affiliated Stomatology Hospital of Kunming Medical University, Kunming, Yunnan Province, China. ${ }^{3}$ Qianxing Road Dental Clinic, The Affiliated Stomatology Hospital of Kunming Medical University, Kunming, Yunnan Province, China. ${ }^{4}$ Department of Prosthodontics, School of Stomatology, Kunming Medical University, Kunming, Yunnan Province, China. ${ }^{5}$ The Affiliated Stomatology Hospital of Kunming Medical University, Kunming, Yunnan Province, China.

Email: dutmanee.ser@mahidol.ac.th,13708425039@163.com
\end{abstract}

\#These 2 authors are the equally contributed to this work

Received: 30 July 2018, Revised and Accepted: 15 October 2018 and 20 December 2018

ABSTRACT

Objective: To investigate the release of bone morphogenetic protein-2 (BMP-2) and collagen type I proteins (COL1) from different sources of demineralized dentine matrix (DDM) and their chemotaxis to mouse osteoprogenitor cells.

Methods: The release kinetic of BMP-2 and COL1 was measured from custom-made DDM (CMDDM) and commercially available DDM (CADDM). Using Urist physicochemical method, CMDDM was collected from the extracted teeth in a certified dental clinic. Levels of BMP-2 and COL1 released were measured at days 1, 2, 3, 5, 7, 9, 11, and 13. Next, mouse osteoprogenitor cells, MC3T3-E1, were cultured with a variety of materials as follows: CMDDM, CADDM, Bio-Oss ${ }^{\circledast}$, and blank control in transwell system. The number of cell migration was determined by crystal violet staining to explore chemotaxis of different DDMs to mouse osteoprogenitor cells.

Results: BMP-2 was detected at $588.32 \pm 14.53 \mathrm{pg} / \mathrm{ml}$ from $5 \mathrm{~g}$ of CMDDM. In the release kinetic assay, the concentration of BMP-2 in the CMDDM group increased rapidly and peaked at $113.9 \mathrm{pg} / \mathrm{ml}$ on day 5, almost four times higher than that of CADDM. The release of COL1 showed similar pattern in both CMDDM and CADDM; however, the amount was significantly higher in the CMDDM group. In cell culture experiment, the number of migrated MC3T3-E1 was ranked as the highest in CMDDM, followed by CADDM and Bio-Oss ${ }^{\circledR}(\mathrm{p}<0.05)$.

Conclusion: CMDDM released BMP-2 and COL1 greater than CADDM, which can induce more osteoblast-like cell migration. These results demonstrated a release kinetic of proteins and osteoinductivity of CMDDM, which supports a benefit of using autogenous bone graft.

Keywords: Demineralized dentine matrix, Chemotaxis, Cell migration, Osteoinduction, bone grafting.

(C) 2019 The Authors. Published by Innovare Academic Sciences Pvt Ltd. This is an open access article under the CC BY license (http://creativecommons. org/licenses/by/4. 0/) DOI: http://dx.doi.org/10.22159/ijap.2019.v11s1.18475

\section{INTRODUCTION}

Every year, an estimated 2 million individuals worldwide suffer from bone defects due to trauma, infection, tumor, or congenital hereditary diseases caused by bony abnormalities. Bone grafts have been predominantly used to treat bony defects. Meanwhile, dental implant technologies are developing rapidly. A number of bone grafting applications have been widely used in clinic; as a result, numerous experiments of bone grafting and bone regeneration are held worldwide [1-3].

Demineralized dentine matrix (DDM) is a kind of dentin which was demineralized and obtained from extracted teeth as a kind of bone graft material [4-6]. The structure and composition of dentin is similar to that of bone, consisting of collagen type I (COL 1) 20\%, hydroxyapatite (HA) $70 \%$, and body fluid $10 \%$ by weight $[7,8]$. Dentin is thought to have a high osteoconductivity since it is a natural mineralized tissue consisting of HA. Furthermore, dentin matrix is expected to exhibit osteoinductivity because it contains bone morphogenetic proteins (BMPs) [8]. BMPs are multifunctional growth factors that belong to the transforming growth factor- $\beta$ superfamily $[9,10]$. BMPs induced mesenchymal stem cells to migrate to a bone-forming site as well as induce their differentiation into an osteoblast to form bone [11,12].
In addition, DDM induces bone and cartilage formation independently by showing an ability to induce new bone formation in challenging location, suggesting a strong evidence of its osteoinduction [13]. However, the local pharmacokinetics are very important for the therapeutic efficacy of BMPs; for example, when BMP-2 is placed at the site of a bone defect, it is quickly dispersed from that site, resulting in minimal effect on bone formation and healing [11]. Therefore, it is necessary to explore an efficient material or delivery system that can slowly release BMPs with steady concentration $[14,15]$. Despite the wide use of DDM in bone defect treatment, the kinetic release of BMPs into the ambient environment has never been investigated before. In our study, we aimed to investigate the amount of BMP-2 and COL1 released from various sources of DDM and to investigate their chemotaxis capacity for osteoblast-like cell in an in vitro study using MC3T3-E1 cells.

\section{METHODS}

Study design

The production of custom-made DDM (CMDDM) was followed and modified from the method of Yagihashi et al. [6] and Yeomans and Urist [16]. Scanning electron microscopy (SEM) was used to visualize the physical characteristics and surface of CMDDM particles. Amount of BMP-2 protein was detected from $5 \mathrm{~g}$ each of commercially available 
DDM (CADDM) and CMDDM, and then the release kinetic of BMP-2 and COL1 proteins was measured from both groups at days 1, 2, 3, 5, $7,9,11$, and 13. Then, we cultured mouse osteoprogenitor cells with the presence of different DDMs and Bio-Oss ${ }^{\circledR}$ bone graft in transwell system, to investigate the chemotaxis of different materials to mouse osteoprogenitor cells. The release of BMP- 2 and COL1 in their mediums was also detected.

\section{Preparation of demineralized dentine matrix}

In this experiment, two kinds of DDM were used, CADDM and CMDDM. CADDM was purchased by luminosity Chuang Bo Biomaterial Company in ShenZhen, China, whereas CMDDM was prepared using undecayed molar or premolar from anonymous patients who came for extraction in the Oral and Maxillofacial Surgery Department, the Affiliated Stomatology Hospital of Kunming Medical University. The principles of Helsinki declaration were followed as the protocol of the study, which was approved by the Ethical Committee of Kunming Medical University.

CMDDM was produced from modified method [6,16]. Briefly, the extracted tooth was washed with cold phosphate-buffered saline (PBS), and the enamel was entirely removed. Then, dentin, cementum, and pulp tissue were crushed into small particles, put into $4^{\circ} \mathrm{C}$ ethyl alcohol/diethyl ether for $4 \mathrm{~h}$, and washed twice with deionized water. $0.6 \mathrm{~mol} / \mathrm{L} \mathrm{HCl}$ was used for demineralization for $48 \mathrm{~h}$ at $4^{\circ} \mathrm{C}$, incubated in $0.01 \mathrm{~mol} / \mathrm{L}$ PBS which contains $10 \mathrm{mM} / \mathrm{L}$ iodoacetic acid in $37^{\circ} \mathrm{C}$ for $72 \mathrm{~h}$, and repeatedly washed using an ultrasonic vibrator. The CMDDM was lyophilized and packaged. Afterward, it was sterilized by 25 kGy cobalt- 60 radiation for $12 \mathrm{~h}$ and stored under $-20^{\circ} \mathrm{C}$

The extraction of BMP-2 was detected by a modified method of Urist et al. [17] and Liu et al. [18]. Briefly, $5 \mathrm{~g}$ of CMDDM was put into $2 \mathrm{M} \mathrm{CaCl}_{2}$ for $24 \mathrm{~h}$ under $4^{\circ} \mathrm{C}$, and then washed by deionized water. It was immersed in $0.5 \mathrm{M}$ ethylenediaminetetraacetic acid for $4 \mathrm{~h}$ and added with $8 \mathrm{M} \mathrm{LiCl}$ for $24 \mathrm{~h}$. After rinsing, CMDDM was put into $6 \mathrm{M}$ urea, $0.5 \mathrm{M} \mathrm{CaCl}_{2}, 1 \mathrm{mM}$ phenylmethylsulfonyl fluoride, and $10 \mathrm{mM} \mathrm{N}$-ethylmaleimide extracting solutions. After $24 \mathrm{~h}$, the liquid supernatant was collected and dialyzed for $24 \mathrm{~h}$ in $0.25 \mathrm{M}$ urea. The dialysate was collected and centrifuged at the speed of $12,000 \mathrm{rpm}$ for $45 \mathrm{~min}$, and the sediment was collected and dissolved in $6 \mathrm{M}$ urea $\left(-0.5 \mathrm{M} \mathrm{CaCl}_{2}\right)$. The precipitate was dissolved and centrifuged for another $45 \mathrm{~min}$. The final supernatant $(190 \mu \mathrm{l})$ was collected for detection. Ten samples of CMDDM were extracted and measured in triplicate $(n=10)$.

Detection of released bone morphogenetic protein-2 and collagen-I $100 \mathrm{mg}$ of each CMDDM and CADDM was added into tubes containing 1-ml serum-free DMEM medium (Hyclone, USA), mixed, labeled, and left in $37^{\circ} \mathrm{C}$ incubator for $1,2,3,5,7,9,11$, and 13 days. Then, 900- $\mu \mathrm{l}$ medium from each tube was removed to centrifuge and kept under $-80^{\circ} \mathrm{C}$. Simple serum-free DMEM medium was used as a blank control. Enzyme-linked immunosorbent assay (ELISA) was used to test the level of BMP-2 (Abcam company, UK) and COL1 (CUSABIO company, USA) according to their manufacturing protocols. In transwell migration experiment, we also detected the release of BMP- 2 and COL1 in their mediums after cultured with different DDMs at days $1-3$, using the same protocol of ELISA

\section{Transwell cell migration assay}

MC3T3-E1 is an osteoblast precursor cell line derived from Mus musculus (mouse) calvaria $[19,20]$, which was bought from Kunming Institute of Zoology. Cell migration assays were evaluated using a two-chamber Transwell system (Transwell Costar, Corning, Acton, MA, USA). Briefly, $1 \times 10^{5} / \mathrm{ml}$ MC3T3-E1s were resuspended in $100-\mu \mathrm{l}$ serum-free DMEM and seeded into the top chamber of the Transwell system, and $600 \mu \mathrm{l}$ of serum-free DMEM with $100 \mathrm{mg}$ DDMs or Bio-Oss ${ }^{\circledR}$ (Geistlich, Switzerland) or none (blank control) was added to the lower chambers (Fig. 1). After $24 \mathrm{~h}, 48 \mathrm{~h}$, and $72 \mathrm{~h}$ incubation at $37^{\circ} \mathrm{C}$ in $5 \%$ $\mathrm{CO}^{2}$, MC3T3-E1 was fixed for $10 \mathrm{~min}$ with $95 \%$ ethyl alcohol and stained with $0.1 \%$ crystal violet for 20 min. For quantification of the migrated cells, five random microscopic fields/filter at $\times 100$ were selected for cell counting. Measurements were done in triplicate: five independent experiments $(n=5)$ and results were presented as mean and standard deviation (SD) in each experiment.

\section{Statistical analysis}

All data were expressed as the mean \pm SD. Statistical analysis for the above assays was performed using ANOVA for repeated measurement analysis of variance and Tukey's HSD test for individual comparison. Statistical Package for the Social Sciences statistical software (version 13.0; SPSS Inc., Chicago, IL, USA) was used in this experiment. The level for statistical significance was set at $\mathrm{p}<0.05$.

\section{RESULTS}

Characteristics of custom-made demineralized dentine matrixs and its amount of bone morphogenetic protein-2

Visual photograph revealed the characteristic of light-yellow dried powder (Fig. 2a). The SEM photographs demonstrated a particle size of 0.4-1.0-mm CMDDM which has relatively smooth surface. Many micro-and macro-fractures were observed in the majority of particles (Fig. 2b). The average amount of BMP-2 that can be extracted from $5 \mathrm{~g}$ of CMDDM was $588.32 \pm 14.53 \mathrm{pg} / \mathrm{ml}$, according to its calibration curve (Supplement Fig. 1 and Table 1). In other words, $1 \mathrm{~g}$ of our CMDDM can produce $117.67 \pm 29.06 \mathrm{pg} / \mathrm{ml}$.

The release kinetic of bone morphogenetic protein- 2 and collagen type I

The release of BMP-2 and COL1 between CMDDM and CADDM was compared and the results are shown in Fig. $3 \mathrm{a}$ and b, respectively. We measured the released amount of BMP- 2 and COL1 according to their calibrating curve of BMP-2 and COL1 (Supplement Figs. 1 and 2). The release of BMP-2 from both DDMs increased rapidly and peaked on day 5 with similar pattern. The released BMP-2 from CMDDM was significantly higher than that from CADDM at all time points (Fig. 3a and Supplement Table 1). In addition, the highest concentration of BMP2 from CMDDM was $113.90 \pm 6.06 \mathrm{pg} / \mathrm{ml}$, whereas that of CADDM was $36.47 \pm 2.93$. For COL1, the release of COL1 from both DDMs increased rapidly and peaked on day 9 with similar pattern. The released COL1 from CMDDM was significantly higher than that from CADDM at days 2 , 5, and 9 (Fig. 3b and Supplement Table 2).

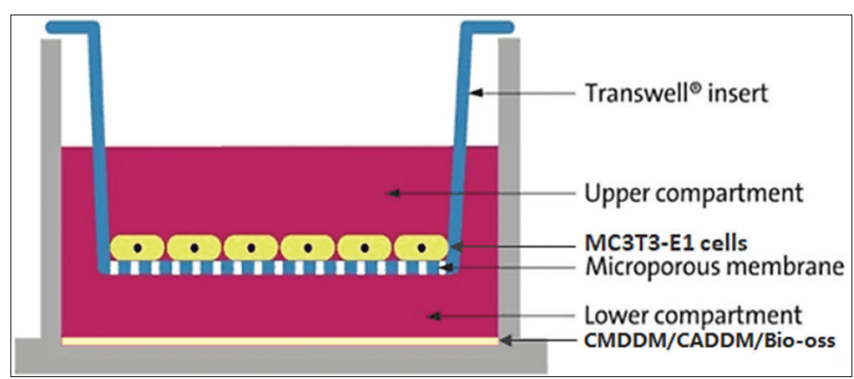

Fig. 1: Transwell-mediated MC3T3-E1 cell migration design

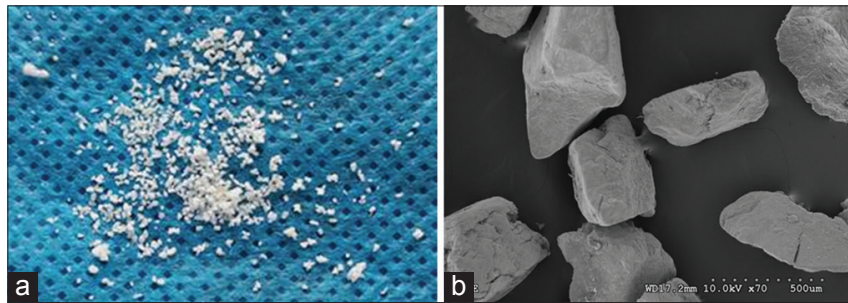

Fig. 2: Physical characteristics of custom-made demineralized dentine matrix (a), Scanning electron microscopy images of commercially available demineralized dentine matrix (b) (×70) 
Migration assay

Next, we investigated the osteoinduction property of DDMs by culturing with MC3T3-E1 osteoblast-like cells. The migrated cells were stained by crystal violet as they appealed at the lower chamber membrane (Fig. 4a). In both CMDDM and CADDM groups, the number of MC3T3-E1 cells that migrated through the membrane was greater than those in Bio-Oss ${ }^{\circledR}$ and blank control (Fig. 4). In quantitative analysis, the average number of migrated MC3T3-E1 cells in CMDDM was significantly higher than that of the CADDM from day 1 to day 3 ( $p<0.05$ ) (Fig. $4 \mathrm{~b}$ ).

During the culture of MC3T3-E1 cells with CMDDM, CADDM, and BioOss ${ }^{\circledR}$, the release of BMP-2 and COL1 in the culturing medium was also measured. The BMP- 2 and COL1 concentrations were steadily increased from day 1 to day 3 (Fig. 5a, b and Supplementary Tables 3, 4). The amount of BMP-2 from CMDDM was significantly higher than that from CADDM on day 2 and day $3(\mathrm{p}<0.05$ ) (Fig. $5 \mathrm{a})$. On day 3 , the highest amount of BMP-2 from CMDDM group was $30.66 \pm 3.77 \mathrm{pg} / \mathrm{ml}$, whereas that of CADDM was $18.66 \pm 0.87(\mathrm{p}<0.05)$ (Supplement Table 3). The amounts of COL1 released from CMDDM group were significantly higher than those from CADDM as early as day 1 and remain higher until day 3. Levels of COL1 are shown in Supplement Table 4. It was noted that the levels of BMP-2 and COL1 released from Bio-Oss ${ }^{\circledR}$ were at similar level with a blank control at all time points.

\section{DISCUSSION}

Natural bones are a complex assembly of parallel type I collagen nanofibrils and HA crystals precipitated on their surface [21]. COL1 has potential as a biomaterial for bone tissue engineering due to its abundance, biocompatibility, high porosity, facility for combination with other materials, easy processing, hydrophilicity, low antigenicity, absorbability in the body, etc. [10]. In addition, among the osteoinductive agents, growth factors are the most important molecules of the healing promotive factors, especially the BMPs [22-24]. DDMs exhibit osteoinductivity because it was reported to be containing BMPs $[5,8]$. Autogenous DDMs are also widely used in treatment in the extraction sockets of mandibular third molars, which showed superior healing of the dental sockets with autogenous DDM $[4,5]$. Many studies applied both mineralized dentin and DDM particles in dental implant surgery and obtained successful bone regeneration results $[13,25]$. Moreover, recent study detected the different degree of mineralized dentin matrix after implant various kinds of DDM in animal. The partially demineralized dentin matrix (PDDM) resulted in higher degree of mineralization when compared with the undemineralized dentin matrix (UDDM) or the completely demineralized dentin (CDDM) [26]. In different methods of DDM preparation, Minamizato et al. described successful clinical applications of autogenous partially demineralized dentin matrix in socket preservation, sinus floor augmentation, and alveolar ridge augmentation [5]. Therefore, it is well acknowledged that application of DDM is useful and advantageous for bone grafting. The size of DDM was also reported to affect bone regeneration.

Nam et al. [27] investigated the effect of different sizes of DDM particles on bone healing in rabbit skull after 2, 4, and 8 weeks of implantations. The histomorphometric results revealed that DDM particles in 0.25$1.0 \mathrm{~mm}$ size activated the majority of new bone formation. From our preparation, we successfully obtained the CMDDM particle size at 0.4-1.0 mm which corresponds with the previous report. Furthermore, many studies have reported that bone graft materials with different particle sizes exhibit different bone-healing abilities [28,29]. Although still controversial, their results suggested that, the smaller the particle

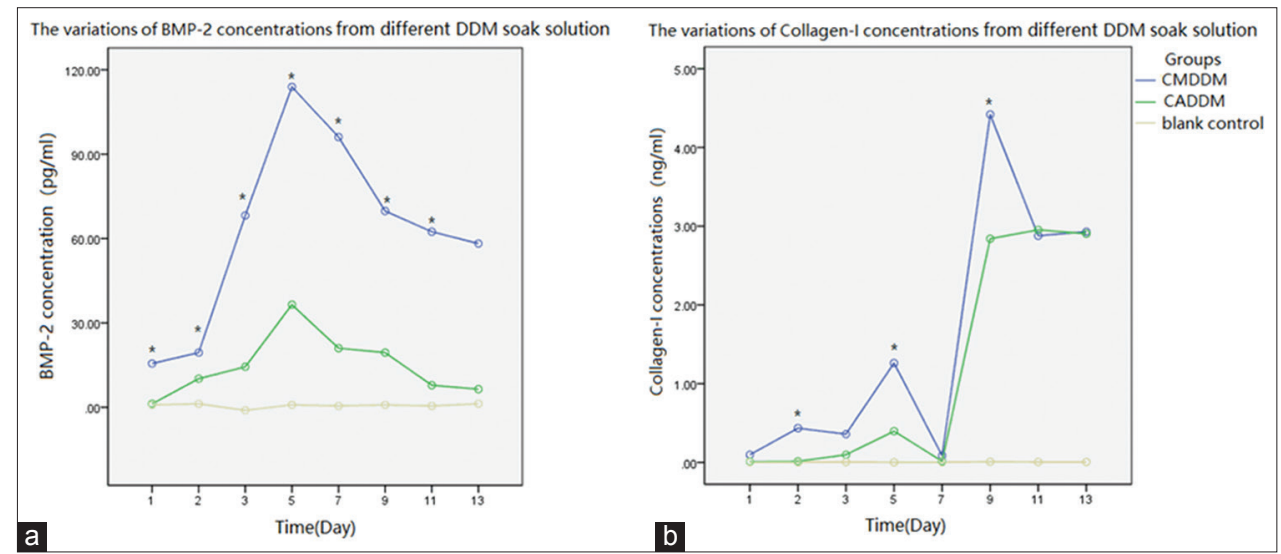

Fig. 3: The released bone morphogenetic protein-2 (a) Collagen type I (b) concentration from various sources of demineralized dentine matrix at different time points, *compared with commercially available demineralized dentine matrix $(p<0.05)$

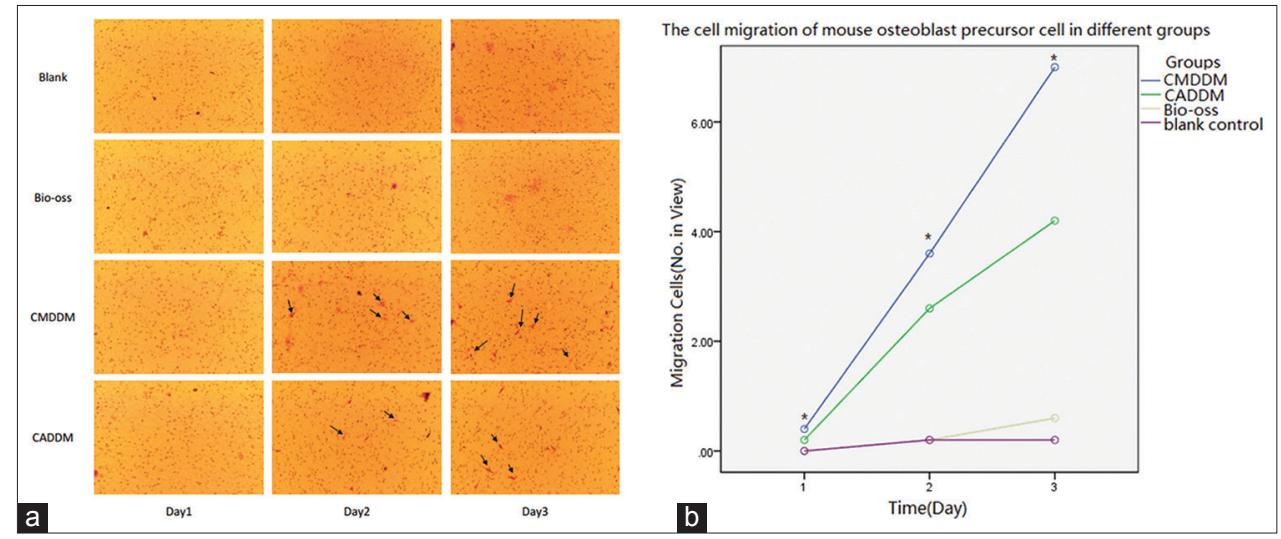

Fig. 4: The representative picture of MC3T3-E1 migration (a) at magnification $\times 100$ and the number of cell migration (No./view), (b) when cultured with different materials from days $1-3$, *compared with commercially available demineralized dentine matrix $(p<0.05)$ 


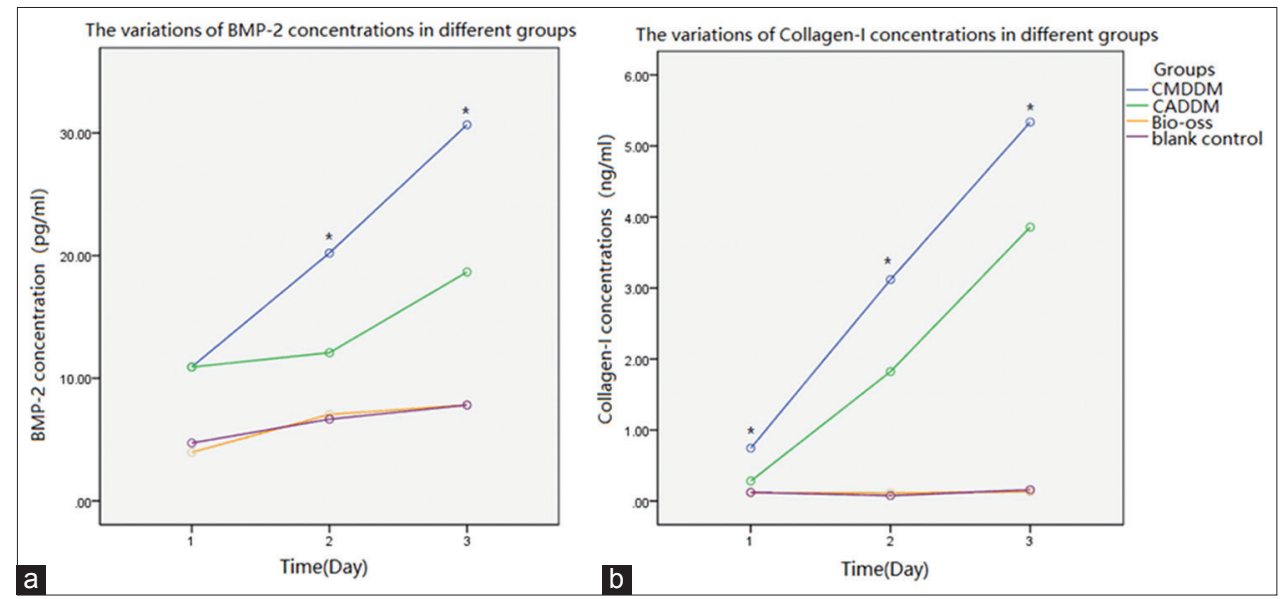

Fig. 5: The bone morphogenetic protein-2 (a) and collagen type I (b) concentrations were measured from culturing medium in different demineralized dentine matrix groups from days 1 to 3 , *compared with commercially available demineralized dentine matrix (p<0.05)

size of the material, the greater the formation of bone by increasing the surface area and more growth factors are secreted to facilitate the formation of new blood vessels. Therefore, it can be suggested that DDMs at a particular size can accelerate the differentiation of mesenchymal cells into osteoblasts, thus assisting the process of bone formation.

BMPs exert significant inductive effects on different stages of bone healing process such as the inflammatory reaction, angiogenesis, the soft and hard callus formation, and bone remodeling, but drawbacks include its rapid degradation and high costs [30,31]. The recombinant BMP-2 is predominantly used in culturing osteoprogenitor cells in order to induce osteoblast differentiation via SMADs signaling pathway. The concentrations vary from 50 to $100 \mathrm{ng} / \mathrm{ml}[32,33]$. In the present study, extracted BMP-2 concentration from fresh dental tissues was detected lesser than those of previous reports, which may be explained by different sources of protein and different chemical treatments. Nevertheless, our results demonstrated that BMP-2 from CMDDM can be slowly released and its concentration can be maintained up to 13 days, emphasizing a great potential of DDMs as a protein carrier material. In addition, the CMDDM released BMP-2 from day 1 to day 13 in relatively high concentration, while the level of BMP-2 from CADDM dropped to baseline at day 13, suggesting that the characteristics of CMDDM are more beneficial than that of CADDM for grafting treatment in the early stage of bone healing. COL1 concentration from both groups were released in the similar pattern and remained high concentration through day 13. It is likely that our extraction method could preserve protein structure and biological activity of BMP-2 protein than other methods that processed by different acid at different duration of decalcification [5,6,26,34]. In addition, the $25 \mathrm{kGy}$ cobalt 60 of radiation was used in this study to ultimately sterilize the CMDDM, whereas CADDM was heat sterilized. The study of Antebi et al. [35] showed that, after bone grafting materials were exposed to 10-50 kGy, their osteoinduction did not alter, but when the radiation amount exceeded $50 \mathrm{kGy}$, the osteoinduction decreased. Thus, it can be explained that the composition and structure of proteins in CMDDM were lesser affected by irradiation in our study.

Cell migration is a manifestation of cell chemotaxis, which makes the cells autonomously move toward or deviate from the stimulation source when stimulated by the signal molecules. A large number of studies have shown that the migration of osteoblast is the key factor to bone fracture healing, and the osteoblast migration is directly related to the formation of new callus [36]. In our study, the MC3T3-E1 cell derived from skull in the mouse was used to differentiate into osteoblasts by osteogenic induction. This experimental design is widely used in bone regeneration experiments $[37,38]$. The culture with DDMs indicated that DDM is nontoxic to cells and revealed a good biocompatibility which promoted MC3T3-E1 cell migration. Different types of commercial bone grafts demonstrated significantly higher proliferative activity and alkaline phosphatase activity in the late stage of bone marrow stem cell culture [3]. It may be due to time required for growth factors to be secreted from the materials, which was the probable cause of the initial lag phase observed in the experimental groups. In our study, CMDDM showed the strongest chemotaxis via the migration of preosteoblast at early day, when compared to CADDM and Bio-Oss ${ }^{\circledR}$. This may be corresponding to the highest amount of released BMP-2 and COL1 from CMDDM that may implicate the result of molecular (BMP-2 and COL1) interaction with the cells. Noted, the levels of BMP-2 and COL1 released from a commonly used bone substitute, Bio-0ss ${ }^{\circledR}$, was shown as similar level with a blank control.

Although most people have experienced tooth extraction, the amount of DDM obtained from clinical site is limited; meanwhile, the commercial DDMs are costly. Under the limitations, further studies should be continued investigating other types of materials which can effectively contain BMPs or other essential growth factors to prolong the protein's release such that it would be a better osteoinductive material for bone regeneration engineering.

\section{CONCLUSION}

CMDDM was successfully prepared from modified protocol and was proved to be able to release BMP-2 and COL1 greater than the CADDM. Therefore, it is plausible that higher level of BMP-2 from the CMDDM could induce more osteoblast-like cell migration which has been suggested for good osteoinductivity. The results of this experiment showed an agreement with other studies that DDMs are competitive with an excellent grafting material.

\section{ACKNOWLEDGMENTS}

This work was supported by Mahidol University and grants from special -jointed fund for applied basic research of Yunnan provincial science and technology of Kunming Medical University (grant no. 2012FB072), Yunnan Provincial health science and technology project (grant no. 2016NS117). We also thank Ying Huang and Hai Zhou for their excellent technical assistance.

\section{CONFLICT OF INTEREST}

All authors have made substantive contribution to this study, and all have reviewed the final paper prior to its submission. The authors declare no potential conflicts of interest and contribution. 


\section{SUPPLEMENT TABLES}

Supplement Table 1: The released bone morphogenetic protein-2 concentration from various sources of demineralized dentine matrix at different time points $(\mathrm{pg} / \mathrm{ml}), n=5, x \pm s$

\begin{tabular}{|c|c|c|c|c|c|c|c|c|}
\hline Groups & 1 day & 2 days & 3 days & 5 days & 7 days & 9 days & 11 days & 13 days \\
\hline CMDDM & $15.56 \pm 1.06$ & $19.44 \pm 2.21$ & $68.22 \pm 7.91$ & $113.90 \pm 6.06$ & $96.09 \pm 6.03$ & $69.77 \pm 1.06$ & $62.41 \pm 2.87$ & $58.00 \pm 1.78$ \\
\hline CADDM & $1.24 \pm 0.87$ & $10.15 \pm 1.62$ & $14.40 \pm 2.37$ & $36.47 \pm 2.93$ & $20.99 \pm 2.21$ & $19.44 \pm 1.73$ & $7.82 \pm 1.73$ & $6.42 \pm 1.25$ \\
\hline Blank control & $0.85 \pm 2.37$ & $1.24 \pm 1.62$ & $1.08 \pm 3.62$ & $0.85 \pm 1.94$ & $0.47 \pm 2.52$ & $0.85 \pm 1.94$ & $0.47 \pm 1.62$ & $1.24 \pm 0.86$ \\
\hline
\end{tabular}

DDM: Demineralized dentine matrix, CADDM: Commercially available DDM, CMDDM: Custom-made DDM group

Supplement Table 2: The released collagen type I concentration from various sources of demineralized dentine matrix at different time points (ng/ml), $n=5, x \pm s$

\begin{tabular}{|c|c|c|c|c|c|c|c|c|}
\hline Groups & 1 day & 2 days & 3 days & 5 days & 7 days & 9 days & 11 days & 13 days \\
\hline CMDDM & $0.10 \pm 0.09$ & $0.43 \pm 0.08$ & $0.36 \pm 0.08$ & $1.26 \pm 0.14$ & $0.09 \pm 0.08$ & $4.42 \pm 0.08$ & $2.88 \pm 0.12$ & $2.93 \pm 0.16$ \\
\hline CADDM & $0.01 \pm 0.01$ & $0.01 \pm 0.01$ & $0.10 \pm 0.15$ & $0.40 \pm 0.09$ & $0.01 \pm 0.01$ & $2.84 \pm 0.19$ & $2.95 \pm 0.09$ & $2.90 \pm 0.09$ \\
\hline Blank control & $0.01 \pm 0.07$ & $0.01 \pm 0.01$ & $0.01 \pm 0.01$ & $0.01 \pm 0.01$ & $0.01 \pm 0.01$ & $0.01 \pm 0.01$ & $0.01 \pm 0.01$ & $0.01 \pm 0.01$ \\
\hline
\end{tabular}

DDM: Demineralized dentine matrix, CADDM: Commercially available DDM, CMDDM: Custom-made DDM group

Supplement Table 3: Bone morphogenetic protein-2 concentrations $(\mathrm{pg} / \mathrm{ml})$ after the different demineralized dentine matrix and Bio-Oss $^{\circledR}$ bone graft cultured with MC3T3-E1 cells, $(n=5), \overline{\mathrm{x}} \pm s$

\begin{tabular}{lll}
\hline Groups & $\mathbf{1}$ day & $\mathbf{2}$ days \\
\hline CMDDM & $10.92 \pm 2.12$ & $20.21 \pm 1.94$ \\
CADDM & $10.92 \pm 0.87$ & $12.08 \pm 1.62$ \\
Bio-Oss ${ }^{\circledR}$ & $3.95 \pm 1.73$ & $7.05 \pm 2.52$ \\
Control & $4.72 \pm 1.37$ & $6.66 \pm 2.74$ \\
\hline
\end{tabular}

DDM: Demineralized dentine matrix, CADDM: Commercially available DDM, CMDDM: Custom-made DDM group

Supplement Table 4: Collagen type I concentrations (ng/ml) in different demineralized dentin matrices and Bio-0ss ${ }^{\circledR}$ bone graft cultured with MC3T3-E1 cells, $(n=5), \bar{x} \pm s$

\begin{tabular}{|c|c|c|c|}
\hline Groups & 1 day & 2 days & 3 days \\
\hline CMDDM & $0.75 \pm 0.06$ & $3.12 \pm 0.07$ & $5.34 \pm 0.07$ \\
\hline CADDM & $0.28 \pm 0.07$ & $1.82 \pm 0.14$ & $3.86 \pm 0.07$ \\
\hline Bio-Oss ${ }^{\circledR}$ & $0.12 \pm 0.01$ & $0.11 \pm 0.01$ & $0.13 \pm 0.02$ \\
\hline Control & $0.12 \pm 0.02$ & $0.08 \pm 0.07$ & $0.16 \pm 0.07$ \\
\hline
\end{tabular}

DDM: Demineralized dentine matrix, CADDM: Commercially available DDM, CMDDM: Custom-made DDM group

\section{SUPPLEMENT FIGURES}

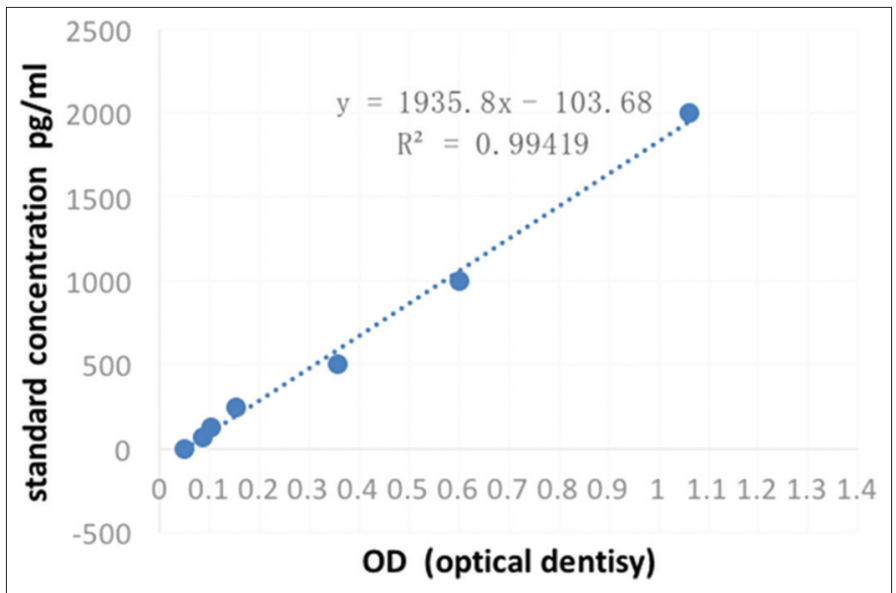

Supplement Fig. 1: Bone morphogenetic protein-2 calibration curve 


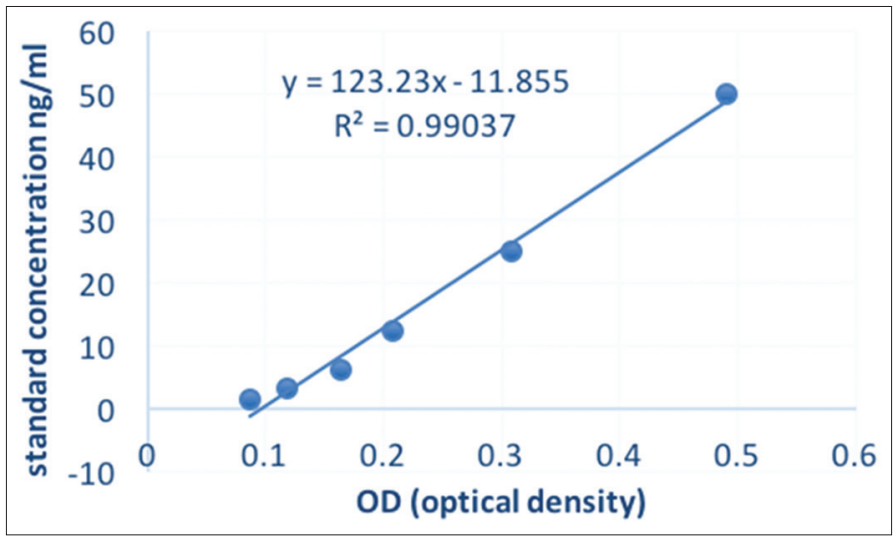

Supplement Fig. 2: Collagen type 1 calibration curve

\section{REFERENCES}

1. Han DS, Chang HK, Park JH, Kim KR, Woo SM. Consideration of bone regeneration effect of stem cells: Comparison between adiposederived stem cells and demineralized bone matrix. J Craniofac Surg 2014;25:189-95.

2. Miron RJ, Bosshardt DD, Laugisch O, Dard M, Gemperli AC, Buser $\mathrm{D}$, et al. In vitro evaluation of demineralized freeze-dried bone allograft in combination with enamel matrix derivative. J Periodontol 2013;84:1646-54.

3. Kumaran ST, Arun KV, Sudarsan S, Talwar A, Srinivasan N. Osteoblast response to commercially available demineralized bone matrices an in vitro study. Indian J Dent Res 2010;21:3-9.

4. de Oliveira GS, Miziara MN, Silva ER, Ferreira EL, Biulchi AP, Alves JB, et al. Enhanced bone formation during healing process of tooth sockets filled with demineralized human dentine matrix. Aust Dent J 2013;58:326-32.

5. Minamizato T, Koga T, I T, Nakatani Y, Umebayashi M, Sumita Y, et al. Clinical application of autogenous partially demineralized dentin matrix prepared immediately after extraction for alveolar bone regeneration in implant dentistry: A pilot study. Int J Oral Maxillofac Surg 2018;47:125-32.

6. Yagihashi K, Miyazawa K, Togari K, Goto S. Demineralized dentin matrix acts as a scaffold for repair of articular cartilage defects. Calcif Tissue Int 2009;84:210-20.

7. Murata M. Collagen biology for bone regenerative surgery. J Korean Assoc Oral Maxillofac Surg 2012;38:321-5.

8. Um IW, Kim YK, Mitsugi M. Demineralized dentin matrix scaffolds for alveolar bone engineering. J Indian Prosthodont Soc 2017;17:120-7.

9. Carreira AC, Lojudice FH, Halcsik E, Navarro RD, Sogayar MC, Granjeiro JM, et al. Bone morphogenetic proteins: Facts, challenges, and future perspectives. J Dent Res 2014;93:335-45.

10. Oryan A, Alidadi S, Moshiri A, Bigham-Sadegh A. Bone morphogenetic proteins: A powerful osteoinductive compound with non-negligible side effects and limitations. Biofactors 2014;40:459-81.

11. Noori A, Ashrafi SJ, Vaez-Ghaemi R, Hatamian-Zaremi A, Webster TJ. A review of fibrin and fibrin composites for bone tissue engineering. Int J Nanomedicine 2017;12:4937-61.

12. Schützenberger S, Schultz A, Hausner T, Hopf R, Zanoni G, Morton T, et al. The optimal carrier for BMP-2: A comparison of collagen versus fibrin matrix. Arch Orthop Trauma Surg 2012;132:1363-70

13. Kim YK, Kim SG, Byeon JH, Lee HJ, Um IU, Lim SC, et al. Development of a novel bone grafting material using autogenous teeth. Oral Surg Oral Med Oral Pathol Oral Radiol Endod 2010;109:496-503.

14. Boerckel JD, Kolambkar YM, Dupont KM, Uhrig BA, Phelps EA, Stevens HY, et al. Effects of protein dose and delivery system on BMPmediated bone regeneration. Biomaterials 2011;32:5241-51

15. Jung T, Lee JH, Park S, Kim YJ, Seo J, Shim HE, et al. Effect of BMP-2 delivery mode on osteogenic differentiation of stem cells. Stem Cells Int 2017;2017:7859184.

16. Yeomans JD, Urist MR. Bone induction by decalcified dentine implanted into oral, osseous and muscle tissues. Arch Oral Biol 1967;12:999-1008.

17. Urist MR, Lietze A, Mizutani H, Takagi K, Triffitt JT, Amstutz J, et al. A bovine low molecular weight bone morphogenetic protein (BMP) fraction. Clin Orthop Relat Res 1982;162:219-32.

18. Liu G, Xu G, Gao Z, Liu Z, Xu J, Wang J, et al. Demineralized dentin matrix induces odontoblastic differentiation of dental pulp stem cells. Cells Tissues Organs 2016;201:65-76.

19. Goyden J, Tawara K, Hedeen D, Willey JS, Oxford JT, Jorcyk CL, et al. The effect of OSM on MC3T3-E1 osteoblastic cells in simulated microgravity with radiation. PLoS One 2015;10:e0127230.

20. Yan XZ, Yang W, Yang F, Kersten-Niessen M, Jansen JA, Both SK, et al. Effects of continuous passaging on mineralization of MC3T3-E1 cells with improved osteogenic culture protocol. Tissue Eng Part C Methods 2014;20:198-204.

21. Currey J. The structure and mechanics of bone. J Mater Sci 2012;47:41-52.

22. Oryan A, Alidadi S, Moshiri, A. Current concerns regarding healing of bone defects. Hard Tissue 2013;2:13.

23. Blokhuis TJ, Calori GM, Schmidmaier G. Autograft versus BMPs for the treatment of non-unions: What is the evidence? Injury 2013;44 Suppl 1:S40-2.

24. Oryan A, Moshiri A. Recombinant fibroblast growth protein enhances healing ability of experimentally induced tendon injury in vivo. J Tissue Eng Regen Med 2014;8:421-31.

25. Lee JY, Kim YK, Yi YJ, Choi JH. Clinical evaluation of ridge augmentation using autogenous tooth bone graft material: Case series study. J Korean Assoc Oral Maxillofac Surg 2013;39:156-60.

26. Koga T, Minamizato T, Kawai Y, Miura KI, Nakatani Y, Sumita Y, et al. Bone Regeneration using dentin matrix depends on the degree of demineralization and particle size. PLoS One 2016;11:e0147235.

27. Nam JW, Kim MY, Han SJ. Cranial bone regeneration according to different particle sizes and densities of demineralized dentin matrix in the rabbit model. Maxillofac Plast Reconstr Surg 2016;38:27.

28. Klüppel LE, Antonini F, Olate S, Nascimento FF, AlbergariaBarbosa JR, Mazzonetto R, et al. Bone repair is influenced by different particle sizes of anorganic bovine bone matrix: A histologic and radiographic study in vivo. J Craniofac Surg 2013;24:1074-7.

29. Pallesen L, Schou S, Aaboe M, Hjørting-Hansen E, Nattestad A, Melsen F, et al. Influence of particle size of autogenous bone grafts on the early stages of bone regeneration: A histologic and stereologic study in rabbit calvarium. Int J Oral Maxillofac Implants 2002;17:498-506.

30. Cottrell JA, Keane O, Lin SS, O'Connor JP. BMP-2 modulates expression of other growth factors in a rat fracture healing model. J Appl Biomed 2014;12:127-35.

31. Ehnert S, Zhao J, Pscherer S, Freude T, Dooley S, Kolk A, et al. Transforming growth factor $\mathrm{b} 1$ inhibits bone morphogenetic protein (BMP)-2 and BMP-7 signaling via upregulation of Ski-related novel protein $\mathrm{N}(\mathrm{SnoN})$ : Possible mechanism for the failure of BMP therapy? BMC Med 2012;10:101.

32. Avery SJ, Sadaghiani L, Sloan AJ, Waddington RJ. Analysing the bioactive makeup of demineralised dentine matrix on bone marrow mesenchymal stem cells for enhanced bone repair. Eur Cell Mater 2017;34:1-4.

33. Rath B, Nam J, Deschner J, Schaumburger J, Tingart M, Grässel S, et al. Biomechanical forces exert anabolic effects on osteoblasts by activation of SMAD 1/5/8 through Type 1 BMP receptor. Biorheology 2011;48:37-48

34. Gomes MF, Valva VN, Vieira EM, Giannasi LC, Salgado MA, VilelaGoulart MG. Homogenous demineralized dentin matrix and plateletrich plasma for bone tissue engineering in cranioplasty of diabetic rabbits: Biochemical, radiographic, and histological analysis. Int J Oral 
Maxillofac Surg 2016;45:255-66

35. Antebi U, Mathor MB, da Silva AF, Guimarães RP, Honda EK. Effects of ionizing radiation on proteins in lyophilized or frozen demineralized human bone. Rev Bras Ortop 2016;51:224-30.

36. Robin M, Almeida C, Azaïs T, Haye B, Illoul C, Lesieur J, et al. Involvement of 3D osteoblast migration and bone apatite during in vitro early osteocytogenesis. Bone 2016;88:146-56.
37. Pang $\mathrm{S}, \mathrm{He} \mathrm{Y}, \mathrm{He} \mathrm{P}$, Luo X, Guo Z, Li H, et al. Fabrication of two distinct hydroxyapatite coatings and their effects on MC3T3-E1 cell behavior. Colloids Surf B Biointerfaces 2018;171:40-8.

38. Saleh LS, Carles-Carner M, Bryant SJ. The in vitro effects of macrophages on the osteogenic capabilities of MC3T3-E1 cells encapsulated in a biomimetic poly(ethylene glycol) hydrogel. Acta Biomater 2018;71:37-48. 